\title{
Semantic Interoperability
}

National Cancer Institute

\section{Source}

National Cancer Institute. Semantic Interoperability. NCI Thesaurus. Code C142682.

The ability of computer systems to share data with unambiguous meaning. 